\title{
Consumer Uncertainty and Price Discrimination through Online Coupons: An Empirical Study of Restaurants in Shanghai
}

\author{
Jie Zhang \\ Fudan University \\ School of Management \\ Shanghai, China 200433 \\ jiezhang2002@fudan.edu.cn \\ Scott J. Savage \\ University of Colorado at Boulder \\ Department of Economics \\ Campus Box 256, Boulder, CO, 80309-0256 \\ scott.savage@colorado.edu \\ Yongmin Chen \\ University of Colorado at Boulder \\ Department of Economics \\ Campus Box 256, Boulder, CO, 80309-0256 \\ yongmin.chen@ colorado.edu
}

May 22, 2013 


\begin{abstract}
We use data from restaurants in Shanghai, China to conduct a new empirical analysis of prices and coupons. Our results show a positive relationship between prices and online coupons. Moreover, the price premium from couponing is higher for restaurants about which consumer values appear to be more uncertain. When consumer uncertainty is high, restaurants that offer coupons have an average price that is about 60 percent higher than similar restaurants that do not issue coupons. When uncertainty is low, restaurants that offer coupons have an average price that is about ten percent higher. These findings are consistent with online couponing in the restaurant industry being used for price discrimination and as a promotional device in the presence of higher uncertainty in consumer valuations.
\end{abstract}

Key words: consumer uncertainty, coupons, price discrimination, price promotion

JEL Classification: L15, L66, L86 


\section{INTRODUCTION}

Why do firms issue coupons? In an influential empirical study, Nevo and Wolfram (2002) explore the relationship between grocery store shelf prices and manufacturers' coupons for ready-to-eat breakfast cereals. They find that prices become lower when coupons are issued, a result that is inconsistent with the standard monopoly price discrimination theory of couponing but can be consistent with models of price discrimination in oligopoly settings (oligopoly models are perhaps more appropriate for the breakfast cereals market). This leaves largely open the question of whether there are other market settings where the price-coupon relationship supports the standard monopoly price discrimination theory.

In this paper, we use data from restaurants in Shanghai, China to conduct a new empirical analysis of prices and coupons. This market has two important characteristics that differ from breakfast cereals. First, many consumers are uncertain about their values for various restaurants, which differ both in qualities and in horizontal attributes. Even for restaurants at a specific quality level, consumer values still vary greatly due to preference diversity and may often be uncertain, especially since many consumers are short-term residents and tourists. Second, for a city with more than 48,000 restaurants, the market may be more properly viewed as one of monopolistic competition: each firm, facing its residual demand, chooses its own price optimally like a monopolist, without considering the effects of its actions on the market price. This market environment thus potentially provides a setting to test the standard monopoly price discrimination role of coupons.

Interestingly, there is a website, www.dianping.com, which provides restaurant information, customer evaluations, customer reviews, and online coupons for almost 40,000 restaurants in Shanghai. Due to possible search costs, uncertain consumers are more likely to 
visit the Dianping website to gather information about a restaurant. The restaurant may then use online coupons for price discrimination, charging a high price for informed (loyal) consumers who are less likely to visit the website but a lower price to attract uncertain consumers who download the online coupon.

We use these data to estimate a descriptive model that relates the average expenditure per customer ("prices") to online couponing, uncertainty in consumer valuations for the restaurant, restaurant quality, and demand and cost factors. Our results show a positive relationship between prices and coupons. Moreover, the price premium from couponing is higher for restaurants about which consumer values appear to be more uncertain. When consumer uncertainty is high, restaurants that offer coupons have an average price that is about 60 percent higher than similar restaurants that do not issue coupons. When uncertainty is low, restaurants that offer coupons have an average price that is about ten percent higher. These findings are consistent with online couponing in the restaurant industry being used for price discrimination and as a promotional device in the presence of higher uncertainty in consumer valuations.

Several other papers have examined empirically the price effects from couponing. Narasimhan (1984) finds a positive correlation between prices and coupons for 20 consumer products, while Levedahl (1986) finds a positive correlation between paper towel prices and coupons. In contrast, Nevo and Wolfram (2002) find that shelf prices for breakfast cereal are lower during periods when coupons are available. Similarly, Anderson and Song (2004) show a negative correlation between the shelf price of packaged goods and coupons when the coupon has a relatively small discount value. Our paper contributes to this literature by offering new evidence from the restaurant market, an environment where consumer uncertainty is important 
and promotions are through online coupons. ${ }^{1}$ Our finding that firms may use the Internet to price discriminate in favour of value-uncertain consumers through online coupons is interesting--it differs from the usual assumption in the literature that the informed consumers receive lower prices and the uninformed consumers are discriminated against (e.g., Varian, 1980).

The rest of the paper is organized as follows. Section 2 discusses the theoretical motivation for our empirical analysis. Section 3 outlines the empirical model and Section 4 describes the data. Results are reported in Section 5, and Section 6 concludes.

\section{THEORETICAL MOTIVATION}

\subsection{Restaurant market}

The restaurant market in Shanghai provides an interesting setting to study why firms issue coupons. Shanghai is the largest city in China, with many tourists and short-term visitors. As of December 2010, it has more than 48,000 restaurants at various quality levels. For restaurants at a certain quality level, consumer valuations still vary greatly due to preference diversity. To extract surplus from consumers who happen to have high valuations, a restaurant has the incentive to charge a high price. But to attract consumers whose valuations are uncertain, a restaurant may need to lower its price. Thus restaurants have incentives to practice price discrimination.

The Internet provides a useful tool both for consumers to learn about restaurants and for restaurants to engage in price discrimination. One popular website for consumers to gather information is www.dianping.com. Dianping is a comprehensive online and physical platform

\footnotetext{
${ }^{1}$ Related research on coupons also includes, for example, Neslin (1990), Neslin and Clarke (1987), Neslin, Henderson, and Quelch (1985), and Vilcassim and Wittink (1987). Our research is also related to the theoretical literature on price discrimination, for example, Anderson and Dana (2009), Holmes (1989), Nahata, Ostaszewski and Sahoo (1990), and Varian (1980).
} 
that collects reviews of restaurants, shops, hotels and other establishments. Potential customers can go through the reviews to get information about a restaurant, including its average expenditure per customer, number of reviews, and average customer evaluations in three dimensions: taste, environment, and service. The website also has information about whether a restaurant offers coupons and, if it does, information about the coupon. Consumers can either print these online coupons or download them to their cellular telephones. They can then redeem their coupon when dining at the restaurant. To the extent that there is search cost to visit the website, it is the uncertain consumers who tend to do so and are thus able to find the coupons. The uncertainty of some consumers and the fact that uncertain consumers are more likely to search www.dianping.com may thus provide both the incentive and a mechanism for restaurants to price discriminate through online coupons.

\subsection{Simple model}

To motivate our empirical analysis, we outline a simple theoretical model that examines optimal restaurant prices with and without coupons. Suppose that the consumer valuation for a restaurant is $V=k+\varepsilon$, where $\varepsilon=-\delta$ or $\delta$, each with probability $1 / 2$, and $\delta>0$. The realizations of $\varepsilon$ are independent for each consumer. We consider the restaurant market in Shanghai as a differentiated market with many firms, where each firm, facing the residual demand of a unit mass of consumers, prices as a monopolist. ${ }^{2}$ A higher-quality restaurant has a higher $k$, and a higher $\delta$ indicates more uncertainty in consumer valuations for the restaurant. Firms can issue online coupons on www.dianping.com where consumers may also evaluate restaurant qualities. There are two types of consumers. A type-I consumer knows the realization

\footnotetext{
${ }^{2}$ We do not attempt to solve an equilibrium model of the market, but rather focus on an individual firm's pricing decision, who takes the market price and its own residual demand as given.
} 
of her $\varepsilon$, whereas a type-II consumer is uncertain about it. The mass of informed consumers (type-I) is $\alpha \in(0,1)$, of which $\alpha \beta, \beta \in[0,1)$, visit Dianping and may have learned their values there, while $\alpha(1-\beta)$ do not visit Dianping. Type-II consumers visit Dianping and remain uncertain about their valuations. ${ }^{3}$ Firms and consumers are assumed to be risk neutral.

First, consider uniform monopoly pricing. In this simple model, only three prices can be potentially optimal under uniform pricing: $p_{u}=k, p_{u}=k+\delta$, or $p_{u}=k-\delta$. Under $p_{u}=k$, informed consumers whose realized $\varepsilon$ is $\delta$ and all uncertain consumers will purchase, resulting in profit $(\alpha / 2+1-\alpha) k$. Under $p_{u}=k+\delta$, only informed consumers whose realized $\varepsilon$ is $\delta$ will purchase, resulting in profit $\alpha(k+\delta) / 2$. Under $p_{u}=k-\delta$, all consumers will purchase, resulting in profit $k-\delta$. It follows that $p_{u}=k$ is optimal if

$$
(\alpha / 2+1-\alpha) k \geq \max \{\alpha(k+\delta) / 2, k-\alpha\}, \text { or } \alpha \leq \min \left\{\frac{2 \delta}{k}, \frac{2(k-\delta)}{k+\delta}\right\}
$$

and $p_{u}=k-\delta$ is optimal if

$$
k-\delta \geq \max \{(\alpha / 2+1-\alpha) k, \alpha(k+\delta) / 2\}, \text { or } \frac{2 \delta}{k} \leq \alpha \leq \frac{2(k-\delta)}{k+\delta} .
$$

For convenience, we make the following simplifying assumption:

$$
\frac{2 \delta}{k} \leq \frac{2 k}{2 k+\delta} \text { and } \alpha \leq \frac{2(k-\delta)}{k+\delta}
$$

which is satisfied if $\delta$ is not too large compared to $k(\delta<k / 2$ necessarily) and $\alpha$ is also not too high (sufficient if $\alpha \leq 2 / 3$ ). Then, $\min \left\{\frac{2 \delta}{k}, \frac{2(k-\delta)}{k+\delta}\right\}=\frac{2 \delta}{k}$, the optimal price under uniform pricing is

\footnotetext{
${ }^{3}$ That is, mass $\alpha(1-\beta)$ of consumers, who know their values for the restaurant, do not visit Dianping. The rest of the consumers visit Dianping, among whom $1-\alpha$ will remain uncertain about their values. So the website provides useful information, but can resolve value uncertainty only for a portion of consumers.
} 


$$
p_{u}^{*}=\left\{\begin{array}{l}
k \text { if } \alpha \leq \frac{2 \delta}{k} \\
k-\delta \text { if } \frac{2 \delta}{k} \leq \alpha \leq \frac{2(k-\delta)}{k+\delta}
\end{array},\right.
$$

and the maximum profit under uniform pricing is

$$
\pi_{u}^{*}=\left\{\begin{array}{l}
\left(1-\frac{\alpha}{2}\right) k \text { if } \alpha \leq \frac{2 \delta}{k} \\
k-\delta \text { if } \frac{2 \delta}{k} \leq \alpha \leq \frac{2(k-\delta)}{k+\delta}
\end{array} .\right.
$$

Next, under price discrimination, the firm can charge a high "regular" price $p_{h}$ and a promotion price through a coupon, $p_{l}$. There are three potentially optimal pairs of prices: $(k+\delta, k),(k+\delta, k-\delta)$, and $(k, k-\delta)$. If $p_{h}=k+\delta$ and $p_{l}=k$, informed consumers who do not visit Dianping and whose realized $V$ is $k+\delta$ will purchase and pay $p_{h}=k+\delta$; among consumers who visit Dianping, those whose realized $V$ is known to be $k+\delta$ and those who remain uncertain will purchase at price $p_{l}=k$. Thus profit under $p_{h}=k+\delta$ and $p_{l}=k$ is

$$
\pi_{1} \equiv \frac{\alpha}{2}(1-\beta)(k+\delta)+\left(\frac{\alpha}{2} \beta+1-\alpha\right) k=\frac{\alpha}{2}(1-\beta) \delta+\left(1-\frac{\alpha}{2}\right) k
$$

and profit under $p_{h}=k+\delta$ and $p_{l}=k-\delta$ is

$$
\pi_{2} \equiv \frac{\alpha}{2}(1-\beta)(k+\delta)+(\alpha \beta+1-\alpha)(k-\delta)
$$

Prices $p_{h}=k$ and $p_{l}=k-\delta$ cannot be optimal under couponing since the profit under these prices is

$$
\frac{\alpha}{2}(1-\beta) k+(\alpha \beta+1-\alpha)(k-\delta)<\pi_{2}
$$

Notice that

$$
\pi_{1}-\pi_{2}=(\alpha \beta+1-\alpha) \delta-\frac{\alpha}{2} \beta k=\alpha\left(-\delta(1-\beta)-\frac{\beta k}{2}\right)+\delta \underset{>}{=} 0
$$




$$
\alpha \underset{<}{>} \frac{2 \delta}{\beta k+(1-\beta)(2 \delta)} \equiv \bar{\alpha}_{1},
$$

where $\bar{\alpha}_{1}>2 \delta / k$ since $k>2 \delta$ from condition (1). Hence, the optimal prices under price discrimination, or couponing, are

$$
\left(p_{h}^{*}, p_{l}^{*}\right)=\left\{\begin{array}{l}
(k+\delta, k) \text { if } \alpha \leq \bar{\alpha}_{1} \\
(k+\delta, k-\delta) \text { if } \alpha>\bar{\alpha}_{1}
\end{array},\right.
$$

with profits

$$
\pi_{d}^{*}=\left\{\begin{array}{l}
\pi_{1} \text { if } \alpha \leq \bar{\alpha}_{1} \\
\pi_{2} \text { if } \alpha>\bar{\alpha}_{1}
\end{array}\right.
$$

Therefore, a seller's optimal prices are either $k$ or $k-\delta$ under uniform pricing, and its optimal prices when issuing coupons are either $(k+\delta, k)$ or $(k+\delta, k-\delta)$. Under uniform pricing, consumers with known high valuation receive positive surplus. By separating (some of) them and raising their price to $p_{h}^{*}=k+\delta$, the seller is able to extract additional surplus from the high-value consumers, while maintaining profits from the other consumers (who are charged $p_{l}^{*}=k$ or $\left.p_{l}^{*}=k-\delta\right)$. Online couponing can thus boost profit. In practice, there could be additional transaction or advertising costs associated with couponing, which may be a reason that only some firms will issue coupons. However, even if it incurs no additional cost, couponing does not always increase profit. For instance, suppose that price is $k$ - $\delta$ under uniform pricing. All consumers purchase at this price. If the "regular" price is raised to $k+\delta$ and a coupon is issued, consumers who know their valuations to be $k-\delta$ may no longer purchase, which negatively affects the firm's profit. Hence, as stated formally in the proposition below, which 
summarizes the optimal prices with or without couponing, if $k$ and $\alpha$ are large, couponing may not be profitable.

Proposition 1 Under condition (1): (i) Suppose that $k \leq 3 \delta$. Then, couponing increases profit. If $\alpha \leq \frac{2 \delta}{k}$, a seller's optimal prices are $p_{u}^{*}=k$ under uniform pricing and $\left(p_{h}^{*}, p_{l}^{*}\right)=(k+\delta, k)$ under couponing; if $\alpha>\frac{2 \delta}{k} ; p_{u}^{*}=k-\delta$ while $\left(p_{h}^{*}, p_{l}^{*}\right)=(k+\delta, k)$ or $(k+\delta, k-\delta)$. (ii) Suppose that $k>3 \delta$. Then couponing increases profit only if $\alpha<\frac{2 \delta}{k-(1-\beta) \delta}$. Under uniform pricing, $p_{u}^{*}=k$ if $\alpha \leq \frac{2 \delta}{k}$ and $p_{u}^{*}=k-\delta$ if $\frac{2 \delta}{k}<\alpha<\frac{2 \delta}{k-(1-\beta) \delta}$, while under couponing $\left(p_{h}^{*}, p_{l}^{*}\right)=(k+\delta, k)$ for all $\alpha<\frac{2 \delta}{k-(1-\beta) \delta}$.

\section{Proof. See Appendix A.}

Proposition 1 suggests two testable predictions consistent with restaurants using coupons for price discrimination: (1) average prices are higher when coupons are issued, and (2) among firms that issue coupons, those for which consumer values are more uncertain (in the sense of having a higher $\delta$ ) will have a higher average price. We next turn to the discussion of our empirical model and data to evaluate these predictions.

\section{EMPRICAL MODEL}

We are interested in the relationship between restaurant prices and coupons, and whether this relationship varies with uncertainty in consumer valuations for the restaurant. Below, we specify and estimate a price equation for restaurants with controls for quality and other cost and demand factors. We can then observe whether, conditional on these factors, there is a systematic 
relationship between prices and coupons, and whether uncertainty in consumer valuations for the restaurant affects this relationship.

The empirical model for restaurant $i=1,2, \ldots, N$ with premise $j=1,2, \ldots J$ at location $l=1,2, \ldots L$ serving food brand $t=1,2, \ldots, T$ is:

$$
\begin{aligned}
\text { PRICE }_{i j l t} & =\phi_{1} \text { COUPON }_{i j l t}+\phi_{2} \text { UNCERTAINTY }_{i j l t}+\phi_{3}\left(\text { COUPON }_{i j l t} \times \text { UNCERTAINTY }_{i j l t}\right) \\
& +\phi_{4} \text { UUALITY }_{i j l t}+\phi_{5} \text { SIZE }_{i j l t}+\eta_{j}+\mu_{l}+v_{t}+u_{i j l t}
\end{aligned}
$$

where PRICE is the average expenditure per customer, COUPON equals one if the restaurant offers an online coupon and zero otherwise, UNCERTAINTY is the uncertainty about consumer valuations for the restaurant, $Q U A L I T Y$ is the quality of the restaurant, SIZE is the potential size of the uncertain (i.e., type-II) consumer group, $\eta_{j}$ are fixed effects that control for unobserved cost and demand factors specific to the premises within the restaurant chain, $\mu_{l}$ are fixed effects that control for cost and demand factors specific to the location, $v_{t}$ are fixed effects that control for cost and demand factors specific to the food brand, $\phi_{1}$ through $\phi_{5}$ are parameters to be estimated, and $u$ is an error.

The empirical model is used for descriptive analysis and does not claim to estimate a causal relationship between PRICE and COUPON. A causal interpretation of the estimated parameters on COUPON, $\phi_{1}$ and $\phi_{3}$, would have to assume that there are no unobserved cost and demand factors that are correlated with the restaurant's decisions about menu prices and the decision to issue an online coupon. Given non-random assignment of coupons across restaurants, this assumption is unlikely to hold. As such, we use fixed effects to control for cost and demand factors specific to the restaurant chain, food brand and location, and interpret $\phi_{1}$ and $\phi_{3}$ as conditional correlations. These estimates, when combined with the predictions from the theoretical model, allow us to make reasonable inferences about why firms offer coupons.

The important economic effect of interest is: 


$$
\partial P R I C E / \partial C O U P O N=\phi_{1}+\phi_{3} U N C E R T A I N T Y
$$

Estimates of $\phi_{1}$ and $\phi_{3}$ from price equation (9) measure the relationship between restaurant prices and online couponing. If the null hypothesis that $\phi_{1}=\phi_{3}=0$ cannot be rejected, this would be taken as evidence that prices are not correlated with coupons. A finding that $\phi_{1}<0$ and $\phi_{3}=0$ would indicate that prices are negatively correlated with coupons, which is inconsistent with static monopoly price discrimination under a broad range of assumptions (Nevo and Wolfram, 2002). A finding that $\phi_{1}>0$ and $\phi_{3}=0$ would indicate that prices are positively correlated with coupons, which is consistent with the practice of price discrimination as described by prediction (1) from our theoretical model. Moreover, the finding that $\phi_{1}>0$ and $\phi_{3}>0$ would indicate that the correlation between prices and coupons becomes more positive with more uncertainty about consumer valuations for the restaurant, as described by prediction (2) from our theoretical model. A finding of this nature indicates that both vertical differentiation and quality uncertainty are more important in restaurant markets relative to say, ready-to-eat breakfast cereals. Specifically, online couponing in the restaurant industry is used for price discrimination and as a promotional device in the presence of higher uncertainty in consumer valuations for the restaurant.

\section{DATA}

\subsection{Sample}

Our sample of restaurants is from the city of Shanghai. Shanghai's population of 23 million is dispersed over 2,477 square miles, with a population density of 9,406 persons per square mile. The "inner ring" is the busiest section of the city with an area of about 46 square miles and population density of about 87,800 persons per square mile, Domestic tourist visits are about 129 million per year and international tourist visits are about 6.29 million per year. 
Approximately 64 percent of Shanghai's households have Internet access and about 123 percent of the population have a cellular telephone, which suggests that some people have more than one cellular telephone. At December 2010, Shanghai was served by approximately 48,000 restaurants and the average expenditure per customer was 88 Yuan or, 13 United States dollars (USD). Table 1 presents selected economic and social characteristics for Shanghai and compares them to the cities of Beijing, New York and Tokyo.

Restaurant data are obtained from Dianping. The company was founded in April, 2003, initially as a restaurant review web site similar to the Zagat Survey of restaurants. Like Yelp.com in the United States, Dianping has more recently expanded its operations to help consumers find different local restaurants and other businesses, and to share their experiences with other consumers. After creating a brief personal profile, contributing consumers log on to

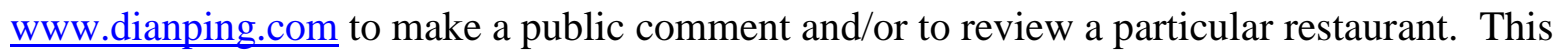
information is merged with restaurant name, location, style of food served and promotional activities, and summarized on the www.dianping.com web site. Visitors to the web site access this information by searching for keywords and/or by directly accessing the drop down-menus for specific topics. At 2009, Dianping was receiving about ten million unique Internet "hits" per month with a growth rate of five percent per month (Bye, 2009).

Dianping's main source of revenue is through paid search results. A restaurant can buy a keyword, such as "hotpot", and the restaurant's name and web link will feature more prominently in the search results for hotpot. At 2009, the most valuable keywords were "Sichuan" and Shanghai business areas, such as "Peoples Park" and "Suzhou Wei", which were retailing for about $\$ 1,000$ USD per month (Bye, 2009). Dianping also earns revenue by providing restaurant coupons on their website. Users can print or download these coupons to 
their cellular telephone and redeem the coupon at the restaurant. The company's other activities include the publication of a restaurant consumption index for Beijing, Shanghai, Nanjing and Hangzhou, the provision of membership cards for consumer specials at participating restaurants, advertising for restaurants and other businesses, and cellular telephone services for restaurant search, consumer reviews and the booking of restaurant tables.

From June 8 to June 12, 2010, we visited the www.dianping.com web site and downloaded place, product and promotion information and customer reviews for 3,745 multipremise restaurants. ${ }^{4}$ This information described several characteristics of the restaurant: name; location; style (or, brand) of food; whether the restaurant issues coupons; coupon conditions ${ }^{5}$; the number of users providing restaurant reviews; expenditure per customer; reviewer's evaluations of the restaurant's food quality, environment and service, respectively; and the reviewer's overall rating of the restaurant. Further analysis of these data revealed that 423 observations in the gross sample had incomplete information. After omitting these observations, the net sample comprised of 3,324 restaurants with complete data for the characteristics described above. The decision to study multi-premise restaurants is deliberate. Because each restaurant has at least two premises, we are able to use restaurant fixed effects in our empirical model to control for unobserved cost and demand factors that are constant between premises within a restaurant chain.

\footnotetext{
${ }^{4}$ At June, 2010, Dianping listed just over 40,000 Shanghai restaurants on its website. However, more than threequarters of these had insufficient customer review information and were not suitable for empirical analysis. ${ }^{5}$ For some of the online coupons in our dataset it is possible to use the information on coupon conditions to calculate the discount value of the coupon in Yuan. For robustness, we use this information in Section 5 to test the relationship between restaurant price and the discount value of the coupon, as opposed to whether the restaurant issues a coupon or not.
} 


\subsection{Variables and summary statistics}

The unit of observation is the "typical meal" sold by the 3,324 restaurant premises within the sample. Restaurant premises are owned and operated by 929 multi-premise restaurants ("chains") at 113 locations throughout Shanghai, serving 17 different food brands. The locations are typically defined by proximity to bus and subway stops, shopping malls, stadiums, universities, business districts and famous landmarks. The food brands are Guizhou, Japanese, Korean, Northeast Chinese, Southeast Asian, Spicy Hunan, Taiwan, Vegetarian, Xinjiang, Buffet, Cantonese, Fast Food, Hotpot, Local Shanghai, Spicy Sichuan, Western, and Other.

The outcome variable of interest is PRICE, which is the average expenditure per customer for customers who logged on to www.dianping.com to review the restaurant. Because it is calculated from the review information provided by contributors to www.dianping.com, PRICE provides a rough proxy for the true average price per customer for all customers of the restaurant.

The key explanatory variables of interest are whether the restaurant offers a coupon and uncertainty about consumer valuations for the restaurant. We define COUPON to equal one if the restaurant offers an online coupon and zero otherwise. Measuring consumer uncertainty is difficult. Ideally, we require a sample of consumer's valuations for Shanghai restaurants to measure consumer uncertainty, but $\underline{w w w . d i a n p i n g . c o m}$ do not have these data or do not readily share it with the public. They do, however, provide average customer evaluations for three independent dimensions of restaurant quality, $k \in\{$ environment, taste, service $\}$. We use these data and Theil's entropy measure to construct the following proxy for uncertainty in consumer valuations for each restaurant premise:

$$
U N C E R T A I N T Y=-\sum_{k} s_{k} \log s_{k}
$$


where $\log$ is the natural log transformation, $s_{k}$ is the ratio of the average customer evaluation of individual dimension $k$ to the sum of average customer evaluations for all three dimensions, environment, taste, and service. For example, when one dimension comprises most of the total evaluation, entropy (UNCERTAINTY) approaches zero. In this restaurant, it is more likely that consumers are uncertain about their valuations for the restaurant with respect to environment, taste and services. When all three dimensions have an equal share of the total evaluation, UNCERTAINTY equals its maximum sample value of 1.099. Here, consumers are likely to be much more certain about their valuations for the restaurant with respect to environment, taste and service.

We measure QUALITY with the average reviewer evaluation of the overall rating of the restaurant on a five-point scale ranging from poor (one) to very good (five). ${ }^{6}$ Our theory and empirical evidence suggest that restaurant prices are increasing in QUALITY. DOWNLOADS, which is the number of downloads of the restaurant's online coupon (that is, SIZE in equation 9), controls for the potential size of the uncertain type-II consumer group. Our theoretical model shows that there is a size threshold for this consumer group $(1-\alpha)$ that makes price discrimination more profitable ("threshold effect"), so to some extent, prices should be increasing in DOWNLOADS. However, because we are using a descriptive model, it is possible that there are less downloads because of lack of interest in the restaurant due to higher prices. When this "reverse causality effect" is large relative to the threshold effect, there may be no empirical relationship between prices and DOWNLOADS or the relationship maybe negative.

\footnotetext{
${ }^{6}$ Because QUALITY and UNCERTAINTY are calculated from user reviews, we need to consider their authenticity. Tau Zhang, the founder of Dianping, notes that fake reviews "can be a problem" and that as the Dianping.com website grows, more people try to spam and trick the website (Bye, 2009). Among other things, Dianping use a credibility score to help verify user reviews. Dianping looks at IP addresses, log in name, password, etc. and the kind of activities users do on the website (e.g., write a review) and assign points to the user. For their review to show on the first page, the user must obtain a high number of credibility points.
} 
Table 2 describes the variables used in equation (9) and Table 3 presents summary statistics. The number of premises per restaurant ranges from two to 53, with a (weighted) average of 9.574 premises per restaurant. Just over 15 percent of restaurant premises offer online coupons. On average, about 449 users per premise logged on to www.dinaping.com to share information on expenditures and evaluations of quality. Average expenditure per customer (PRICE) was 73.17 Yuan (or, 10.80 USD) and average quality (QUALITY) was 3.681 out of five. Customers appear to be reasonably certain about their valuations for restaurants. Although UNCERTAINTY ranges from 0.809 to 1.099 , the average value of 1.086 is closer to 1.099 , which indicates more certainty about consumer valuations with respect to environment, taste and service. ${ }^{7}$ The average number of coupon downloads per restaurant premise (DOWNLOADS) ranged from zero to 10,018 , with an average of 227 . The average number of downloads, conditional on the restaurant offering a coupon, is $1,473 .^{8}$

\subsection{Preliminary empirical evidence}

Our theory suggests two testable predictions consistent with restaurants using coupons for price discrimination. First, prices are higher when coupons are issued, and second, among firms that issue coupons, those for which consumer valuations are more uncertain, will have a higher price. To examine these predictions, we first present some simple comparisons of prices between restaurants that do and no not offer coupons and between restaurants with high- versus low-uncertainty about consumer valuations. Low-uncertainty (high-uncertainty) restaurant-

\footnotetext{
${ }^{7}$ Note that is equivalent to a low value for $\delta$ in our theoretical model and supports simplifying assumption (1).

${ }^{8}$ The number of customer visits to the typical restaurant premise's online coupon link ranged from zero to 36,805 , with an average of 1,042 . The number of customer visits to the typical restaurant premise's online coupon link, conditional on the restaurant offering coupons, is 6,737 .
} 
premise observations are defined as those where UNCERTAINTY is less than (greater than) the sample's $50^{\text {th }}$ percentile.

Table 4 presents group mean comparison tests of restaurant prices. Panel (1) shows that the average price in restaurants that offer coupons is about 9.27 Yuan (or, 12.9 percent) higher than restaurants that do not offer coupons. Panel (2) shows that for high-uncertainty restaurants, the average price in restaurants that offer coupons is about 16.75 Yuan (or, 27.7 percent) higher, and panel (3) shows no significant difference in prices in low-uncertainty restaurants. By indicating that prices may be positively related to couponing and that the relationship is more pronounced for high-uncertainty restaurants, these preliminary results provide some support for prediction's (1) and (2) from our theory. In the next section, we explore these relationships further with a regression approach that controls for quality, cost and demand factors.

\section{RESULTS}

The empirical model and data described in Section 3 and Section 4 are used to investigate the relationship between prices and coupons in the Shanghai restaurant market. We estimate several model specifications of the price equation (9): with and without measures of quality and consumer uncertainty; with and without the interaction term between couponing and consumer uncertainty; with additional controls for unobserved quality that may be correlated with the prices and the propensity to issue coupons (for example, provision of wireless Internet access in the restaurant, number of hours restaurant is open); and with an alternative measure of coupons that indicates the discount value of the coupon in Yuan. Because the sample observations represent averages and are likely to vary by the number of elements used to calculate the averages, we expect the error variances from equation (5) to vary with the number of customers 
contributing reviews to www.dianping.com (RESPONSES). We improve the efficiency of our estimator by addressing this form of heteroskedasticity with a weighted least squares (WLS) procedure that divides price equation (9) through by $\sqrt{\text { RESPONSES }}$.

\subsection{Baseline results}

WLS estimates of the double-log price equation are presented in Table 5. The first column shows the baseline model specification (i) where we regress restaurant prices on COUPON, the number of downloads of the restaurant's online coupon (DOWNLOADS), and restaurant-, brand- and location-specific fixed effects. The estimated coefficient on DOWNLOADS is negative and significant at the one percent level. This finding suggests that the threshold effect for price discrimination may be outweighed by the reverse causality effect. The estimated coefficient on COUPON is positive (0.108), significant at the one percent level, and supports prediction (1) from our theory. Specifically, this estimate indicates that the average price at restaurants that offer online coupons is about eleven percent higher than similar restaurants that do not issue coupons.

Model (ii) includes QUALITY in the price equation to control for differences in overall quality between restaurant premises. The second column of Table 5 shows the results from model (ii) where we regress prices on COUPON, the average reviewer evaluation of the "overall rating" of the restaurant (QUALITY), DOWNLOADS, and restaurant-, brand- and locationspecific fixed effects. The results are qualitatively similar to those reported for model (i). The

estimated coefficient on DOWNLOADS remains negative, and, as expected, the estimated coefficient on QUALITY indicates a positive correlation between prices and quality. The estimated coefficient on COUPON is 0.116 and is significant at the five percent level. 
The next two model specifications consider the price effects from uncertainty about consumer valuations for the restaurant. Model (iii) regresses prices on COUPON, the entropy measure of consumer uncertainty (UNCERTAINTY), QUALITY, DOWNLOADS, and restaurant-, brand- and location-specific fixed effects. To be consistent with the theoretical model, we multiply logUNCERTAINTY by negative one before including it in the price equation so that an increase in this variable indicates that consumer valuations are more uncertain (in the sense of having a higher $\delta$ ). As shown in column three, the inclusion of UNCERTAINTY in the price equation has little impact on the estimated coefficients for COUPON, QUALITY and DOWNLOADS. The estimated coefficient on UNCERTAINTY is negative and significant at the one percent level. This result implies that, after controlling for online couponing, greater uncertainty is associated with lower prices, which is consistent with proposition (1) from our theoretical model that prices are non-increasing in uncertainty. The estimated coefficient on COUPON is 0.117 , significant at the one percent level, and continues to indicate that the average price at restaurants that offer coupons is about eleven to twelve percent higher than similar restaurants that do not offer coupons.

Until now, model specification's (i) through (iii) have been used to test prediction (1) from our theory. It is not possible to comment on prediction (2) because the interaction term between coupons and consumer uncertainty was excluded from the specification of the price equation. Model (iv) addresses this by regressing prices on COUPON, UNCERTAINTY, COUPON $\times U N C E R T A I N T Y, Q U A L I T Y, D O W N L O A D S$, and restaurant-, brand- and locationspecific fixed effects. Column four of Table 5 shows that the estimated coefficients on COUPON and COUPON $\times U N C E R T A I N T Y$ are both statistically significant and result in:

$$
\text { DlogPRICE/OCOUPON }=0.254+1.626 \log U N C E R T A I N T Y .
$$


When evaluated at the mean value for UNCERTAINTY, the estimate of $\partial \log P R I C E / \partial C O U P O N$ is positive (0.120), significant at the five percent level, and indicates that the average price at restaurants that offer coupons is about twelve percent higher than similar restaurants that do not offer coupons. This result is almost identical to the correlations between average prices and online couponing reported for model specification's (i) through (iii). Interestingly, the estimate of $\partial \log P R I C E / \partial C O U P O N$ shows that the correlation between prices and coupons becomes more positive when consumer valuations are more uncertain for the restaurant. Some sense of this effect is obtained by evaluating $\partial \log P R I C E / \partial C O U P O N$ at the sample minimum and maximum values for UNCERTAINTY. When evaluated at the minimum value (i.e., "less consumer uncertainty"), the average price for restaurants offering coupons is about ten percent higher than restaurants that do not offer coupons. When evaluated at the maximum value (i.e., "more consumer uncertainty"), the average price for restaurants offering coupons is about 60 percent higher than restaurants without coupons. ${ }^{9}$ Figure 1 plots the correlation between prices and coupons over the sample range for uncertainty about consumer valuations.

\subsection{Robustness}

It is possible that our results in Table 5 reflect differences in some additional (unmeasured) services provided by restaurants. Specifically, restaurant's that issue online coupons may also provide other online services within their restaurant that raise both quality and prices. For robustness, we include WIRELESS (equals one when the restaurant premise provides patrons with wireless access for cellular telephones and laptop computers and zero otherwise) in

\footnotetext{
${ }^{9}$ Because the sample mean for UNCERTAINTY is close to the sample maximum, it is possible that relatively low values for this variable maybe driving our results in column four of Table 5. To test this possibility, we estimated model specification (iv) on a subsample that excluded all observations with a value of UNCERTAINTY below the tenth percentile. The results, not reported, are qualitatively similar to those in column four of Table 3.
} 
model specification (v) to control for restaurant-premise differences in the provision of additional information technology services. The number of hours per day that a restaurant is open may also be a an indicator of quality and the propensity to issue coupons. For example, restaurants that are open all day are more likely to be low-valuation, high volume ("fast food") restaurants and are less likely to target potential customers with online coupons. As an additional robustness check, we also include BREAKFAST (equals one when the restaurant is open for breakfast, and zero otherwise) and $L U N C H$ (equals one when the restaurant is open for lunch, and zero otherwise) in model specification (v) to control for these potentially omitted quality effects. $^{10}$

Because the data on wireless access and number of hours open were not available for all restaurants, we estimate the price equation on the reduced sample of 2,932 restaurant-premises. For comparison with Table 5, column one of Table 6 reports estimates of model specification (iv) on the reduced sample without any of the additional control variables. We then sequentially add WIRELESS to model (v) (column two of Table 6), WIRELESS and BREAKFAST to model (vi) (column three of Table 6) and WIRELESS, BREAKFAST and LUNCH to model (vii) (column four of Table 6) to model (vii). Overall, the results are qualitatively similar to those reported in Table 5. The estimated coefficient on COUPON is positive and significant across all four specifications. The estimated coefficient on COUPON $\times U N C E R T A I N T Y$ is also positive across all four specifications but marginally insignificant in model's (vi) and (vii). A comparison of model (vii) results in Table 6 to model (iv) results in Table 5 show that the inclusion of the additional controls results in smaller estimates of $\partial \log P R I C E / \partial C O U P O N$. When evaluated at the mean value for UNCERTAINTY, the estimate of $\partial \log P R I C E / \partial C O U P O N$ indicates that the

\footnotetext{
${ }^{10}$ About 19 percent of restaurants in the sample provide wireless access to patrons. All restaurants open for dinner, about 99 percent open for lunch and about ten percent open for breakfast.
} 
average price for restaurants offering coupons is about ten percent higher than restaurants that do not offer coupons. When evaluated at the minimum value, the average price for restaurants offering coupons is about nine percent higher than restaurants that do not offer coupons, although this affect marginally insignificant at the ten percent level. When evaluated at the maximum value, the average price for restaurants offering coupons is about 52 percent higher than restaurants without coupons.

We also estimated the price equation (5) with an alternative measure of online couponing. Of the 514 restaurant-premises in our sample that issue coupons, 291 provide specific information on the discount value of the coupon, 221 indicate that the coupon is a "special" that allows the customer to buy one course and get something free, and two provided no information. Following Nevo and Wolfram (2002), we use this information to construct DOLLARS OFF, which equals the discount value of the coupon in Yuan, and zero when no coupon is offered. ${ }^{11}$

Estimates of model specification's (i) through (iv) using DOLLARS OFF as the measure of online couponing are presented in Table $7 .^{12}$ The price equation estimates are qualitatively similar to those reported in Table 5 and Table 6. Focusing on column's (i) through (iii), we observe that the estimated coefficients on DOLLARS OFF are about 0.056 and significant at the one percent level across all three model specification's (i) through (iii). These results suggest that the average price for restaurants that offer coupons is higher than similar restaurants that do not, and that the average price is increasing in the discount value of the coupon. In model (iv),

\footnotetext{
${ }^{11}$ About 75 percent of these observations had information on the value of the coupon in Yuan and the remaining observations had information on the percentage discount. We converted the percentage discount to Yuan by multiplying the percentage discount by the average expenditure per restaurant per capita. For coupons that offered consumers a choice of a Yuan discount or a percentage discount, we used the Yuan discount. When multiple coupons were issued by a restaurant premise, for example, dinner versus lunch or weekend versus weekdays, we calculated the average discount across all coupons. For the 291 observations with information on the value of the coupon, the conditional mean PRICE was 83.15 Yuan and the conditional mean DOLLARS OFF was 47.58 Yuan. ${ }^{12}$ The 221 observations with a special coupon are excluded, as are the two observations with no precise coupon information, which leaves an effective sample size for estimation of 3,101.
} 
the estimated coefficients on DOLLARS OFF and DOLLARS OFF $\times U N C E R T A I N T Y$ are both statistically significant and result in:

$$
\text { DlogPRICE/DlogDOLLARS OFF = } 0.115+0.639 \log U N C E R T A I N T Y .
$$

When evaluated at the mean value for UNCERTAINTY, the estimate of $\partial \log P R I C E / \partial \log$ DOLLARS OFF is positive (0.063), significant at the one percent level, and indicates that a ten percent increase in the discount value of the coupon is associated with a 0.63 percent increase in the average price. When evaluated at the minimum value, a ten percent increase in coupon value is associated with a 0.55 percent increase in the average price. When evaluated at the maximum value, a ten percent increase in coupon value is associated with a 2.51 percent increase in the average price.

\section{Conclusion}

This paper has conducted a new empirical study of why firms issue coupons, using a unique data set of restaurants in Shanghai and a novel approach that focuses on the role of consumer uncertainty. A distinctive feature of the market is that a sufficient portion of consumers are uncertain about their valuations of specific restaurants. Online coupons are issued through a website that provides restaurant information. To the extent that there are costs to search the website, consumers who are informed of their valuations are less likely to conduct the costly search. A restaurant may thus use online coupons to engage in price discrimination, charging a higher "regular" price for higher-value consumers and a lower price with coupons to uncertain consumers as a way of promotion. In support of the predictions from this theoretical reasoning, our empirical analysis finds that there is a positive relationship between prices and 
online coupons, and that the price premium from couponing is higher for restaurants about which consumer values appear to be more uncertain.

As Nevo and Wolfram (2002) points out, more economic analysis of couponing is much needed, due to its importance in firms' promotion activities and in comparison to the substantial work by economists devoted to the study of advertising, the other predominant form of marketing. Our paper complements Nevo and Wolfram's study of prices and couponing in the breakfast cereals industry. In contrast to their finding that prices are negatively related to couponing, we found a positive relationship in the restaurant market in Shanghai. It appears that two key features of the Shanghai restaurant market, some product uncertainty and a large number of differentiated producers (so that each producer may take its residual demand as given when setting price), might have contributed to the difference in the findings. Taken together, the empirical evidences suggest that the nature of products and of market structure can play important roles in determining the motives to issue coupons and the price-couponing relationship.

\section{References}

Anderson, E. and Dana, J. 2009. "When is Price Discrimination Profitable." Management Science, 55(6), 980-989.

Anderson, E. and Song, I. 2004. "Coordinating Price Reductions and Coupon Events.” Journal of Marketing Research, 41, 411-422.

Bye, A. 2009. “Tao Zhang from Dianping.com”, http://meetinnovators.com/2009/07/02/taozhang-from-dianping-com/. 
Holmes, T. 1989. “The Effects of Third-Degree Price Discrimination in Oligopoly.” American Economic Review, 79, 244--250.

Levedahl, J. 1986. "Profit-Maximizing Pricing of Cents-Off Coupons: Promotion or Price

Discrimination?" Quarterly Journal of Business and Economics, 25, 56--70.

Nahata, B., Ostaszewski, K., and Sahoo, P. 1990. "Direction of Price Changes in Third-Degree Price Discrimination.” American Economic Review, 80, 1254--1258.

Narasimhan, C. 1984. “A Price Discrimination Theory of Coupons.” Marketing Science, 3, 128-147.

Neslin, S. 1990. “A Market Response Model for Coupon Promotions.” Marketing Science, 9, $125--145$.

------and Clarke, D. 1987. "Relating the Brand Use Profile of Coupon Redeemers to Brand and Coupon Characteristics.” Journal of Advertising Research, 27, 23--32.

------, Henderson, C., and Quelch, J. 1985. “Consumer Promotions and the Acceleration of Product Purchases.” Marketing Science, 4, 147--165.

Nevo, A., and Wolfram, C. 2002. "Why do Manufacturers Issue Coupons? An Empirical Analysis of Breakfast Cereals.” RAND Journal of Economics, 33, 319--339.

Varian, H. 1980. “A Model of Sales.” American Economic Review, 70, 651-659.

Vilcassim, N. and Wittink, D. 1987. "Supporting a Higher Shelf Price Through Coupon Distributions." Journal of Consumer Marketing, 4, 29--39.

\section{Appendix. Proof of Proposition 1.}

For $\alpha \leq \frac{2 \delta}{k}, p_{u}^{*}=k$ and $\left(p_{h}^{*}, p_{l}^{*}\right)=(k+\delta, k)$, and thus 


$$
\pi_{d}^{*}-\pi_{u}^{*}=\pi_{1}-\left(1-\frac{\alpha}{2}\right) k=\frac{\alpha}{2}(1-\beta) \delta+\left(1-\frac{\alpha}{2}\right) k-\left(1-\frac{\alpha}{2}\right) k>0
$$

for $\alpha \frac{2 \delta}{k}<\alpha<\bar{\alpha}_{1}, p_{u}^{*}=k-\delta$ while $\left(p_{h}^{*}, p_{l}^{*}\right)=(k+\delta, k)$, and thus

$$
\begin{aligned}
\pi_{d}^{*}-\pi_{u}^{*} & =\pi_{1}-(k-\delta)=\frac{\alpha}{2}(1-\beta) \delta+\left(1-\frac{\alpha}{2}\right) k-(k-\delta) \\
& =-\frac{\alpha}{2}[k-(1-\beta) \delta]+\delta \underset{<}{>} 0 \text { if } \alpha \underset{>}{<-(1-\beta) \delta} \equiv \frac{2 \delta}{k} \bar{\alpha}_{2} ;
\end{aligned}
$$

and for $\bar{\alpha}_{1} \leq \alpha \leq \frac{2(k-\delta)}{k+\delta}, p_{u}^{*}=k-\delta$ while $\left(p_{h}^{*}, p_{l}^{*}\right)=(k+\delta, k-\delta)$, and thus

$$
\begin{aligned}
\pi_{d}^{*}-\pi_{u}^{*} & =\pi_{2}-(k-\alpha)=\frac{\alpha}{2}(1-\beta)(k+\delta)+(\alpha \beta+1-\alpha)(k-\delta)-(k-\alpha) \\
& =-\frac{\alpha}{2}(1-\beta)(3 \delta-k) \underset{<}{>} 0 \text { if } \begin{aligned}
< & > \\
> &
\end{aligned} .
\end{aligned}
$$

Notice that $\bar{\alpha}_{1} \underset{<}{=} \bar{\alpha}_{2}$ if $\underset{<}{=} 3 \delta$.

Therefore, suppose that $k \leq 3 \delta$. Then $\bar{\alpha}_{1} \leq \bar{\alpha}_{2}$, and the optimal uniform prices under couponing are

$$
\left\{p_{u}^{*},\left(p_{h}^{*}, p_{l}^{*}\right)\right\}=\left\{\begin{array}{l}
\{k,(k+\delta, k)\} \text { if } \alpha \leq \frac{2 \delta}{k} \\
\{k-\delta,(k+\delta, k)\} \text { if } \frac{2 \delta}{k}<\alpha<\bar{\alpha}_{1} \\
\{k-\delta,(k+\delta, k-\delta)\} \text { if } \bar{\alpha}_{1} \leq \alpha \leq \frac{2(k-\delta)}{k+\delta}
\end{array} .\right.
$$

Suppose that $k>3 \delta$. Then $\bar{\alpha}_{1}>\bar{\alpha}_{2}$, and 


$$
\left\{p_{u}^{*},\left(p_{h}^{*}, p_{l}^{*}\right)\right\}=\left\{\begin{array}{l}
\{k,(k+\delta, k)\} \text { if } \alpha \leq \frac{2 \delta}{k} \\
\{k-\delta,(k+\delta, k)\} \text { if } \frac{2 \delta}{k}<\alpha<\bar{\alpha}_{2} \\
p_{u}^{*}=k-\delta \text { and no couponing if } \bar{\alpha}_{2} \leq \alpha \leq \bar{\alpha}_{1} \\
p_{u}^{*}=k-\delta \text { and no couponing if } \bar{\alpha}_{1} \leq \alpha \leq \frac{2(k-\delta)}{k+\delta}
\end{array},\right.
$$

where for $\bar{\alpha}_{2} \leq \alpha \leq \bar{\alpha}_{1}, p_{u}^{*}=k-\delta$ while $\left(p_{h}^{*}, p_{l}^{*}\right)=(k+\delta, k)$, but $\pi_{d}^{*}=\pi_{1}<\pi_{u}^{*}$ for $\bar{\alpha}_{2} \leq \alpha \leq \bar{\alpha}_{1}$;

and for $\bar{\alpha}_{1} \leq \alpha \leq \frac{2(k-\delta)}{k+\delta}, p_{u}^{*}=k-\delta$, while $\left(p_{h}^{*}, p_{l}^{*}\right)=(k+\delta, k-\delta)$, but $\pi_{d}^{*}=\pi_{2}<\pi_{u}^{*}$ for

$k>3 \delta$.

TABLE 1

SELECTED ECONOMIC AND SOCIAL CHARACTERISTICS

\begin{tabular}{lcccc}
\hline & Beijing & Shanghai & New York & Tokyo \\
\hline${\text { Area }\left(\text { miles }^{2} \text { ) }\right.}$ & 6,488 & 2,447 & 301 & 844 \\
Population (million) & 19.6 & 23.0 & 8.21 & 13.0 \\
Population density (persons per mile ${ }^{2}$ ) & 3,023 & 9,406 & 27,289 & 15,383 \\
Gross domestic product per capita (USD) & 10,314 & 11,563 & 57,173 & $64,722^{\mathrm{a}}$ \\
Percent of adult population unemployed & 1.4 & 4.3 & 8.2 & 4.5 \\
Percent of adult population with college education & 31.5 & 22.0 & 27.4 & 27.1 \\
Percent of adult population with high school education & 21.2 & 21.0 & 72.3 & n.a. \\
Domestic tourists per year (million) & 180 & 124 & 39.0 & n.a. \\
International tourists per year (million) & 4.90 & 6.29 & 9.70 & 4.76 \\
Percent of homes with Internet access & 69.4 & 64.5 & $81.5^{\mathrm{b}}$ & 85.9 \\
Percent of population with cellular telephone & 121 & 123 & $88.4^{\mathrm{b}}$ & 140 \\
Number of restaurants & 36,658 & $\approx 48,000$ & 23,499 & $\approx 60,000$ \\
Expenditure per person per dinner (USD) & 10.00 & 13.00 & 41.81 & 70.64 \\
\hline
\end{tabular}

NOTES. Data are from 2008 through $2010 .{ }^{a}$ denotes $2002 .{ }^{b}$ denotes New York state. n.a. is not available. USD is United States dollars.

SOURCES. http://www.stats-sh.gov.cn/frontshgl/18677.html;

http://quickfacts.census.gov/qfd/states/36/3651000.html;

http://www.bea.gov/iTable/iTable.cfm?reqid=70\&step=1\&isuri=1\&acrdn=2;

http://cityroom.blogs.nytimes.com/2008/07/30/report-finds-big-divide-in-internet-access/;

http://www.bjstats.gov.cn/xwgb/tjgb/pcgb/201105/t20110504_201364.htm;

http://www.toukei.metro.tokyo.jp/tnenkan/tn-eindex.htm. http://search.japantimes.co.jp/cgi-bin/nb20020516a6.html; and http://hraunfoss.fcc.gov/edocs_public/attachmatch/DOC-301823A1.pdf. 
TABLE 2

VARIABLE DESCRIPTIONS

\begin{tabular}{|c|c|}
\hline Variable & Description \\
\hline PRICE & $\begin{array}{l}\text { Average expenditure per customer (Yuan) for all customers } \\
\text { who logged on to www.dianping.com to review the } \\
\text { restaurant. }\end{array}$ \\
\hline COUPON & $\begin{array}{l}\text { One when the restaurant offers an online coupon, and zero } \\
\text { otherwise. }\end{array}$ \\
\hline QUALITY & $\begin{array}{l}\text { Average overall rating of the restaurant per customer for all } \\
\text { customers who logged on to www.dianping.com to review } \\
\text { the restaurant. Overall rating ranges from one (poor) to five } \\
\text { (very good). }\end{array}$ \\
\hline UNCERTAINTY & $\begin{array}{l}\text { Entropy measure of uncertainty of consumer valuations for } \\
\text { the restaurant with respect to three dimensions of quality: } \\
\text { environment; taste; and services. }\end{array}$ \\
\hline DOWNLOADS & $\begin{array}{l}\text { Number of downloads of the restaurant's online coupon from } \\
\text { www.dianping.com. Zero if the restaurant does not offer an } \\
\text { online coupon. }\end{array}$ \\
\hline DOLLARS OFF & $\begin{array}{l}\text { Discount value of the coupon in Yuan. Zero if the restaurant } \\
\text { does not offer an online coupon. }\end{array}$ \\
\hline PREMISES & Number of premises within the restaurant chain. \\
\hline WIRELESS & $\begin{array}{l}\text { One when the restaurant provides wireless telephone and } \\
\text { Internet access, and zero otherwise. }\end{array}$ \\
\hline BREAKFAST & $\begin{array}{l}\text { One when the restaurant is open for breakfast, and zero } \\
\text { otherwise. }\end{array}$ \\
\hline$L U N C H$ & $\begin{array}{l}\text { One when the restaurant is open for lunch, and zero } \\
\text { otherwise. }\end{array}$ \\
\hline RESPONSES & $\begin{array}{l}\text { Number of contributing customers who log on to } \\
\text { www.dianping.com to review the restaurant. }\end{array}$ \\
\hline
\end{tabular}


TABLE 3

SUMMARY STATISTICS

\begin{tabular}{lcccc}
\hline & Mean & $\begin{array}{c}\text { Standard } \\
\text { deviation }\end{array}$ & Minimum & Maximum \\
\hline Full sample $(n=3,324)$ & 73.17 & 57.26 & 7 & 545 \\
PRICE & 0.155 & 0.362 & 0 & 1 \\
COUPON & 3.680 & 0.870 & 1 & 5 \\
QUALITY & 1.086 & 0.020 & 0.809 & 1.099 \\
UNCERTAINTY & 227.0 & 909.7 & 0 & 10,018 \\
DOWNLOADS & 9.574 & 11.44 & 2 & 53 \\
PREMISES & 449.0 & 992.2 & 5 & 19,429 \\
RESPONSES & & & & \\
COUPON SAmple $(n=514)$ & 80.52 & 42.80 & 9 & 397 \\
PRICE & 4.057 & 0.673 & 1 & 5 \\
QUALITY & 1.093 & 0.007 & 1.036 & 1.099 \\
UNCERTAINTY & 1,473 & 1,882 & 0 & 10,018 \\
DOWNLOADS & 11.52 & 14.38 & 2 & 53 \\
PREMISES & 745.8 & 1,265 & 5 & 11,215 \\
RESPONSES & & &
\end{tabular}

TABLE 4

GROUP MEAN COMPARISON TESTS OF PRICES

\begin{tabular}{|c|c|c|c|c|c|c|c|c|}
\hline \multicolumn{3}{|c|}{ All restaurants (1) } & \multicolumn{3}{|c|}{ High-uncertainty restaurants (2) } & \multicolumn{3}{|c|}{ Low-uncertainty restaurants (3) } \\
\hline Group & Obs. & Mean & Group & Obs. & Mean & Group & Obs. & Mean \\
\hline No coupon & 1,810 & $\begin{array}{l}71.74 \\
(1.12)\end{array}$ & No coupon & 1,502 & $\begin{array}{l}60.41 \\
(1.22)\end{array}$ & No coupon & 1,308 & $\begin{array}{l}84.76 \\
(1.89)\end{array}$ \\
\hline Coupon & 514 & $\begin{array}{l}81.01 \\
(1.92)\end{array}$ & Coupon & 144 & $\begin{array}{l}77.15 \\
(3.09)\end{array}$ & Coupon & 370 & $\begin{array}{l}82.51 \\
(2.38)\end{array}$ \\
\hline Difference & & $\begin{array}{l}9.27^{* * *} \\
(2.74)\end{array}$ & Difference & & $\begin{array}{l}16.75^{* * *} \\
(4.05)\end{array}$ & Difference & & $\begin{array}{l}-2.25 \\
(3.78) \\
\end{array}$ \\
\hline
\end{tabular}

NOTES. High-uncertainty (low-uncertainty) restaurant-premise observations are those where UNCERTAINTY is less than (greater than) the sample's $50^{\text {th }}$ percentile. Standard errors in parenthesis. ${ }^{* * * *}$ significant at the 0.1 level. Obs. is number of observations. 
TABLE 5

WLS ESTIMATES OF PRICE EQUATION

\begin{tabular}{|c|c|c|c|c|}
\hline & Model (i) & Model (ii) & Model (iii) & Model (iv) \\
\hline \multirow[t]{2}{*}{ COUPON } & $0.108^{*}$ & $0.116^{* * *}$ & $0.117^{* * *}$ & $0.254^{* * * *}$ \\
\hline & $(0.057)$ & $(0.102)$ & $(0.135)$ & $(0.094)$ \\
\hline \multirow[t]{2}{*}{ UNCERTAINTY } & & & $-2.039^{* * *}$ & $-2.225^{* * *}$ \\
\hline & & & $(0.290)$ & $(0.308)$ \\
\hline \multirow[t]{2}{*}{ COUPON $\times$ UNCERTAINTY } & & & & $1.626^{*}$ \\
\hline & & & & (0.904) \\
\hline \multirow[t]{2}{*}{ QUALITY } & & $0.142^{* * * *}$ & $0.135^{* * *}$ & $0.135^{* * *}$ \\
\hline & & $(0.018)$ & $(0.018)$ & $(0.018)$ \\
\hline \multirow[t]{2}{*}{$D O W N L O A D S$} & $-0.025^{* * *}$ & $-0.027^{* * * *}$ & $-0.029^{* * *}$ & $-0.027^{* * *}$ \\
\hline & (0.009) & (0.009) & (0.009) & (0.009) \\
\hline \multirow[t]{2}{*}{ CONSTANT } & $3.605^{* * * *}$ & $3.378^{* * *}$ & $3.271^{* * *}$ & $3.261^{* * * *}$ \\
\hline & $(0.161)$ & $(0.162)$ & $(0.161)$ & $(0.161)$ \\
\hline \multirow[t]{2}{*}{$\partial \log P R I C E / \partial C O U P O N(\max )$} & & & & $0.598^{* *}$ \\
\hline & & & & $(0.273)$ \\
\hline \multirow[t]{2}{*}{ DlogPRICE/OCOUPON (mean) } & & & & $0.120^{* *}$ \\
\hline & & & & $(0.056)$ \\
\hline \multirow[t]{2}{*}{$\partial \log P R I C E / \partial C O U P O N(\min )$} & & & & $0.101^{*}$ \\
\hline & & & & $(0.057)$ \\
\hline Adjusted $\mathrm{R}^{2}$ & 0.971 & 0.972 & 0.972 & 0.972 \\
\hline
\end{tabular}

NOTES. Dependent variable is the log of average expenditure per customer (logPRICE). ${ }^{* * *}$ significant at the 0.01 level. ${ }^{* *}$ significant at the 0.05 level. ${ }^{*}$ significant at the 0.1 level. Weights for WLS estimation are the number of contributing customers who log on to www.dianping.com to review a restaurant (RESPONSES). Standard errors for $\partial \log P R I C E / \partial C O U P O N$ are calculated with the delta method. Restaurant fixed effects, brand fixed effects and location fixed effects not reported. 3,324 restaurant-premise observations. 
TABLE 6

WLS ESTIMATES OF PRICE EQUATION WITH ADDITIONAL CONTROLS

\begin{tabular}{|c|c|c|c|c|}
\hline & Model (iv) & Model (v) & Model (vi) & Model (vii) \\
\hline \multirow[t]{2}{*}{ COUPON } & $0.250^{* * * *}$ & $0.250^{* * * *}$ & $0.219^{* * * *}$ & $0.219^{* * *}$ \\
\hline & $(0.010)$ & $(0.010)$ & $(0.010)$ & $(0.010)$ \\
\hline \multirow[t]{2}{*}{ UNCERTAINTY } & $-2.525^{* * *}$ & $-2.502^{* * *}$ & $-2.386^{* * *}$ & $-2.383^{* * *}$ \\
\hline & $(0.340)$ & $(0.340)$ & $(0.339)$ & $(0.339)$ \\
\hline \multirow[t]{2}{*}{ COUPON $\times$ UNCERTAINTY } & $1.782^{*}$ & $1.809^{*}$ & 1.411 & 1.404 \\
\hline & $(0.969)$ & $(0.969)$ & $(0.968)$ & $(0.968)$ \\
\hline \multirow[t]{2}{*}{ QUALITY } & $0.142^{* * *}$ & $0.143^{* * *}$ & $0.140^{* * * *}$ & $0.140^{* * *}$ \\
\hline & $(0.020)$ & $(0.020)$ & $(0.020)$ & $(0.020)$ \\
\hline \multirow[t]{2}{*}{$D O W N L O A D S$} & $-0.026^{* * *}$ & $-0.026^{* * *}$ & $-0.026^{* * *}$ & $-0.026^{* * *}$ \\
\hline & $(0.009)$ & $(0.009)$ & $(0.009)$ & $(0.009)$ \\
\hline \multirow[t]{2}{*}{ WIRELESS } & & $0.013^{*}$ & $0.013^{*}$ & $0.013^{*}$ \\
\hline & & $(0.007)$ & $(0.007)$ & $(0.007)$ \\
\hline \multirow[t]{2}{*}{ BREAKFAST } & & & $-0.059^{* * *}$ & $-0.059^{* * *}$ \\
\hline & & & $(0.013)$ & $(0.013)$ \\
\hline \multirow[t]{2}{*}{$L U N C H$} & & & & -0.017 \\
\hline & & & & $(0.040)$ \\
\hline \multirow[t]{2}{*}{ CONSTANT } & $3.211^{* * *}$ & $3.210^{* * *}$ & $3.223^{* * *}$ & $3.240^{* * *}$ \\
\hline & $(0.165)$ & $(0.165)$ & $(0.164)$ & $(0.169)$ \\
\hline \multirow[t]{2}{*}{ DlogPRICE/OCOUPON (max) } & $0.628^{* *}$ & $0.633^{* *}$ & $0.518^{*}$ & $0.516^{*}$ \\
\hline & $(0.293)$ & $(0.292)$ & $(0.292)$ & $(0.292)$ \\
\hline \multirow[t]{2}{*}{ dlogPRICE/OCOUPON (mean) } & $0.104^{*}$ & $0.101^{*}$ & $0.104^{*}$ & $0.103^{*}$ \\
\hline & $(0.058)$ & $(0.058)$ & $(0.058)$ & $(0.058)$ \\
\hline \multirow[t]{2}{*}{ DlogPRICE/OCOUPON (min) } & 0.083 & 0.079 & 0.087 & 0.087 \\
\hline & $(0.059)$ & $(0.059)$ & $(0.059)$ & $(0.059)$ \\
\hline Adjusted $\mathrm{R}^{2}$ & 0.974 & 0.974 & 0.974 & 0.974 \\
\hline
\end{tabular}

NOTES. Dependent variable is the log of average expenditure per customer (logPRICE). ${ }^{* * * *}$ significant at the 0.01 level. ${ }^{* *}$ significant at the 0.05 level. " significant at the 0.1 level. Weights for WLS estimation are the number of contributing customers who log on to www.dianping.com to review a restaurant (RESPONSES). Standard errors for $\partial \log P R I C E / \partial C O U P O N$ are calculated with the delta method. Restaurant fixed effects, brand fixed effects and location fixed effects not reported. 2,932 restaurant-premise observations. 
TABLE 7

WLS ESTIMATES OF PRICE EQUATION WITH ALTERNATIVE MEASURE OF COUPONS

\begin{tabular}{|c|c|c|c|c|}
\hline & Model (i) & Model (ii) & Model (iii) & Model (iv) \\
\hline \multirow[t]{2}{*}{ DOLLARS OFF } & $0.056^{* * * *}$ & $0.056^{* * * *}$ & $0.057^{* * * *}$ & $0.115^{* * *}$ \\
\hline & $(0.018)$ & $(0.018)$ & $(0.018)$ & $(0.032)$ \\
\hline \multirow[t]{2}{*}{ UNCERTAINTY } & & & $-1.991^{* * *}$ & $-2.213^{* * *}$ \\
\hline & & & $(0.298)$ & $(0.314)$ \\
\hline \multirow[t]{2}{*}{ DOLLARS OFF $\times$ UNCERTAINTY } & & & & $0.639^{* *}$ \\
\hline & & & & $(0.288)$ \\
\hline \multirow[t]{2}{*}{ QUALITY } & & $0.153^{* * *}$ & $0.146^{* * *}$ & $0.145^{* * *}$ \\
\hline & & $(0.019)$ & $(0.019)$ & $(0.019)$ \\
\hline \multirow[t]{2}{*}{ DOWNLOADS } & $-0.058^{* * *}$ & $-0.059^{* * *}$ & $-0.061^{* * * *}$ & $-0.062^{* * * *}$ \\
\hline & $(0.012)$ & $(0.012)$ & $(0.012)$ & $(0.012)$ \\
\hline \multirow[t]{2}{*}{ CONSTANT } & $3.181^{* * *}$ & $2.958^{* * *}$ & $2.974^{* * *}$ & $2.974^{* * *}$ \\
\hline & $(0.579)$ & $(0.571)$ & $(0.566)$ & $(0.565)$ \\
\hline \multirow[t]{2}{*}{ DlogPRICE/ODOLLARS OFF (max) } & & & & $0.251^{* * *}$ \\
\hline & & & & $(0.089)$ \\
\hline \multirow[t]{2}{*}{ DlogPRICE/ODOLLARS OFF (mean) } & & & & $0.063^{* * *}$ \\
\hline & & & & $(0.018)$ \\
\hline \multirow[t]{2}{*}{ DlogPRICE/ODOLLARS OFF (min) } & & & & $0.055^{* * *}$ \\
\hline & & & & $(0.018)$ \\
\hline Adjusted $\mathrm{R}^{2}$ & 0.970 & 0.971 & 0.971 & 0.971 \\
\hline
\end{tabular}

NOTES. Dependent variable is the log of average expenditure per customer (logPRICE). ${ }^{* * * *}$ significant at the 0.01 level. *** significant at the 0.05 level. * significant at the 0.1 level. Weights for WLS estimation are the number of contributing customers who log on to www.dianping.com to review a restaurant (RESPONSES). Standard errors for

$\partial \log P R I C E / \partial C O U P O N$ are calculated with the delta method. Restaurant fixed effects, brand fixed effects and location fixed effects not reported. 3,011 restaurant-premise observations. 
FIGURE 1

PRICE PREMIUM FROM COUPON AND UNCERTAINTY IN CONSUMER VALUATIONS

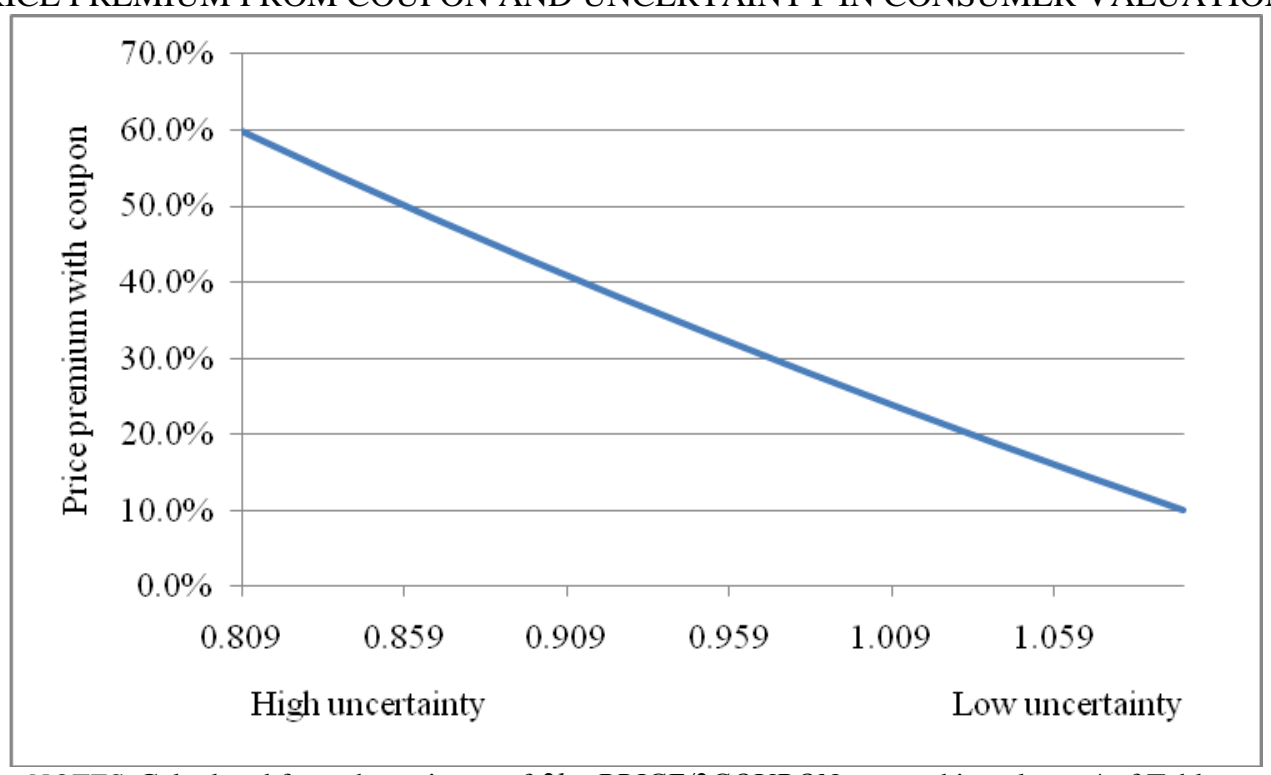

NOTES. Calculated from the estimate of $\partial \log P R I C E / \partial C O U P O N$ reported in column 4 of Table 5. Consumer uncertainty (UNCERTAINTY) ranges from the sample minimum of 0.809 (high uncertainty) to the sample maximum of 1.089 (low uncertainty). 